\title{
Comparison of the Pullout Strength of Different Pedicle Screw Designs and Augmentation Techniques in an Osteoporotic Bone Model
}

\author{
Gorkem Kiyak ${ }^{1}$, Tevfik Balikci ${ }^{2}$, Ahmed Majid Heydar ${ }^{3}$, Murat Bezer ${ }^{3}$ \\ ${ }^{I}$ Department of Orthopaedic Surgery, Academic Hospital, Istanbul, Turkey \\ ${ }^{2}$ Department of Orthopaedic Surgery, Medistate Hospital Kavactk, Istanbul, Turkey \\ ${ }^{3}$ Department of Orthopaedic Surgery, Marmara University Faculty of Medicine, Istanbul, Turkey
}

\begin{abstract}
Study Design: Mechanical study.
Purpose: To compare the pullout strength of different screw designs and augmentation techniques in an osteoporotic bone model. Overview of Literature: Adequate bone screw pullout strength is a common problem among osteoporotic patients. Various screw designs and augmentation techniques have been developed to improve the biomechanical characteristics of the bone-screw interface.

Methods: Polyurethane blocks were used to mimic human osteoporotic cancellous bone, and six different screw designs were tested. Five standard and expandable screws without augmentation, eight expandable screws with polymethylmethacrylate (PMMA) or calcium phosphate augmentation, and distal cannulated screws with PMMA and calcium phosphate augmentation were tested. Mechanical tests were performed on 10 unused new screws of each group. Screws with or without augmentation were inserted in a block that was held in a fixture frame, and a longitudinal extraction force was applied to the screw head at a loading rate of $5 \mathrm{~mm} /$ min. Maximum load was recorded in a load displacement curve.

Results: The peak pullout force of all tested screws with or without augmentation was significantly greater than that of the standard pedicle screw. The greatest pullout force was observed with 40-mm expandable pedicle screws with four fins and PMMA augmentation. Augmented distal cannulated screws did not have a greater peak pullout force than nonaugmented expandable screws. PMMA augmentation provided a greater peak pullout force than calcium phosphate augmentation.

Conclusions: Expandable pedicle screws had greater peak pullout forces than standard pedicle screws and had the advantage of augmentation with either PMMA or calcium phosphate cement. Although calcium phosphate cement is biodegradable, osteoconductive, and nonexothermic, PMMA provided a significantly greater peak pullout force. PMMA-augmented expandable 40-mm four-fin pedicle screws had the greatest peak pullout force.
\end{abstract}

Keywords: Screw; Pedicle; Expandable; Osteoporosis; Augmentation

Received Jan 5, 2017; Revised Apr 18, 2017; Accepted May 20, 2017

Corresponding author: Gorkem Kiyak

Department of Orthopaedic Surgery, Academic Hospital, Nuhkuyusu cad. No: 9434664 Üsküdar, Istanbul, Turkey

Tel: +90-5325908834, Fax: +90-2165549800, E-mail: drgorkemkiyak@gmail.com 


\section{Introduction}

Pedicle screw placement is routine in spinal fixation and usually results in stable, secure fixation. Low mineral density at the bone-screw interface significantly weakens pedicle screw fixation among osteporotic patients, ultimately resulting in screw loosening and loss of secure fixation [1]. Different screw designs and augmentation techniques are available to overcome this problem. Expandable and cannulated pedicle screws have been designed to increase the pullout force of pedicle screws and have been tested along with polymethylmethacrylate (PMMA) or calciumbased bone substitute augmentation. Design differences in the cannulated portion of screws, which is used to inject PMMA, may affect the pullout force, but direct comparisons have not been published. There are no data on how the design of expandable screws affects the pullout force, and while PMMA augmentation has been used in previous studies, only a few have also evaluated augmentation with calcium-based bone cement [2-8]. The present study was a comprehensive comparison of the effect of the screw design and augmentation method on the screw pullout force.

\section{Materials and Methods}

\section{Pedicle screws and test groups}

The pedicle screw design, the number tested, and the augmentation techniques are shown in Table 1. Six screws were expandable and one was cannulated. The $20-\mathrm{mm}$ and $40-\mathrm{mm}$ expandable screw designs with either two $(2 \mathrm{~F}$ $20 \mathrm{~mm}$ and $2 \mathrm{~F} 40 \mathrm{~mm}$ ) or four (4F $20 \mathrm{~mm}$ and $4 \mathrm{~F} 40 \mathrm{~mm}$ ) fins were specially manufactured, and a standard pedicle screw was included as a control.

The expandable screws had a cannulated center into which an expansion pin was placed. The cannula was used to inject either PMMA or calcium phosphate cement before inserting the expansion pin (Fig. 1A). The cannulated screw had a central conduit with two 10-mm long and 2-mm wide holes at the distal end. Either PMMA or calcium phosphate cement was injected through the cannula (Fig. 1B). The standard pedicle screw was a conical, self-tapping screw. The design variables including thread pitch and width, proximal root radius, distal root radius, proximal half angle, and distal half angle were kept constant among the screws (Table 2). All screws were made of a titanium alloy according to American Standard of Testing Materials (ISO 5832-3, Ti6AI4V-ELI; AK Steel, Butler County, OH, USA).

Table 1. Pedicle screws, augmentation, and test groups

\begin{tabular}{|c|c|c|c|c|}
\hline Test group & Screw type & No. of screw & Polymethylmethacrylate augmentation & Calcium phosphate augmentation \\
\hline 1 & STD & 10 & $x$ & $x$ \\
\hline 2 & $2 \mathrm{~F} 20 \mathrm{~mm}$ & 10 & $x$ & $x$ \\
\hline 3 & $2 \mathrm{~F} 40 \mathrm{~mm}$ & 10 & $x$ & $x$ \\
\hline 4 & 4F $20 \mathrm{~mm}$ & 10 & $x$ & $x$ \\
\hline 5 & $4 \mathrm{~F} 40 \mathrm{~mm}$ & 10 & $x$ & $x$ \\
\hline 6 & $2 \mathrm{~F} 20 \mathrm{~mm}$ & 10 & $\sqrt{ }$ & $x$ \\
\hline 7 & $2 \mathrm{~F} 40 \mathrm{~mm}$ & 10 & $\sqrt{ }$ & $x$ \\
\hline 8 & 4F $20 \mathrm{~mm}$ & 10 & $\sqrt{ }$ & $x$ \\
\hline 9 & $4 \mathrm{~F} 40 \mathrm{~mm}$ & 10 & $\sqrt{ }$ & $x$ \\
\hline 10 & $2 \mathrm{~F} 20 \mathrm{~mm}$ & 10 & $x$ & $\sqrt{ }$ \\
\hline 11 & $2 \mathrm{~F} 40 \mathrm{~mm}$ & 10 & $x$ & $\sqrt{ }$ \\
\hline 12 & $4 \mathrm{~F} 20 \mathrm{~mm}$ & 10 & $x$ & $\sqrt{ }$ \\
\hline 13 & $4 \mathrm{~F} 40 \mathrm{~mm}$ & 10 & $X$ & $\sqrt{ }$ \\
\hline 14 & CAN & 10 & $\sqrt{ }$ & $x$ \\
\hline 15 & CAN & 10 & $X$ & $\sqrt{ }$ \\
\hline
\end{tabular}

STD, standard pedicle screw; CAN, cannulated screw. 


\section{Pullout tests}

Cellular polyurethane foam (Pacific Research Laboratories, Vashon, WA, USA) conforming to ASTM F18399720 [9] was used because it prevents the varying results that can occur with biomechanical tests using cadaver bone $[10,11]$. Foam with a $0.16 \mathrm{gm} / \mathrm{cm}^{3}$ density, $23 \mathrm{Mpa}$ compressive modulus, $2.3 \mathrm{MPa}$ compressive strength, and $86 \%$ porosity was used to simulate cancellous bone with severe osteoporosis. Screws were inserted into the center
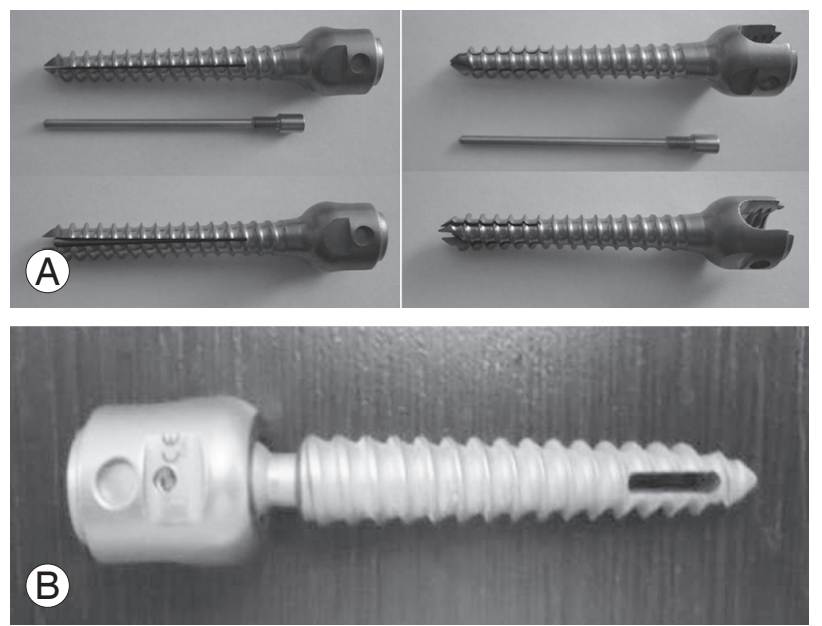

Fig. 1. (A) Expandable screws with fins of different length and number. (B) Cannulated pedicle screw. of $4 \times 6 \times 6 \mathrm{~cm}$ foam block (Fig. 2) and were inserted with a length of $45 \mathrm{~mm}$ without pretapping. PMMA (CEMFIX cement; Teknimed SA, Bigorre, France) or calcium phosphate cement (Calsibon synthetic calcium phosphate bone substitute; Biomet Deutschland $\mathrm{GmbH}$, Berlin, Germany) used as augmentation was injected with a $50 \mathrm{~mL}$ syringe and plastic adapter. Approximately 2-3 mL of cement was injected with hand pressure through the central bore of the screws (Fig. 3). The amount of cement delivered was limited by the amount of pressure developed by the syringe during injection. Bone cements are heat sensitive, and handling and temperature reduce the final setting time. Consequently, surgeons should rely on experience

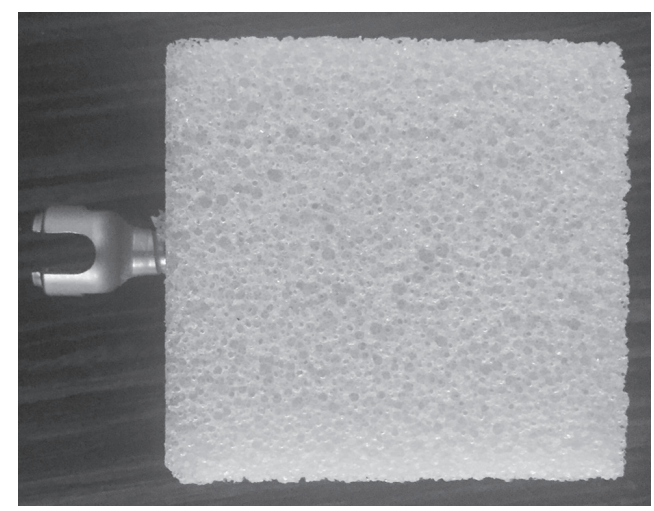

Fig. 2. Screw inserted in the center of the polyurethane foam block.

Table 2. Design characteristics of the pedicle screws

\begin{tabular}{|c|c|c|c|c|c|c|}
\hline Feature & STD & $2 \mathrm{~F} 20 \mathrm{~mm}$ & $2 \mathrm{~F} 40 \mathrm{~mm}$ & 4F 20 mm & 4F $40 \mathrm{~mm}$ & CAN \\
\hline Thread width (mm) & 0.1 & 0.1 & 0.1 & 0.1 & 0.1 & 0.1 \\
\hline Proximal root radius (mm) & 0.8 & 0.8 & 0.8 & 0.8 & 0.8 & 0.8 \\
\hline Distal root radius (mm) & 0.8 & 0.8 & 0.8 & 0.8 & 0.8 & 0.8 \\
\hline Proximal half angle $\left({ }^{\circ}\right)$ & 5 & 5 & 5 & 5 & 5 & 5 \\
\hline Distal half angle $\left({ }^{\circ}\right)$ & 25 & 25 & 25 & 25 & 25 & 25 \\
\hline Conical angle $\left({ }^{\circ}\right)$ & 2 & 2 & 2 & 2 & 2 & 2 \\
\hline Outer diameter (neck, mm) & 7 & 7 & 7 & 7 & 7 & 7 \\
\hline Inner diameter (neck, mm) & 6.1 & 6.1 & 6.1 & 6.1 & 6.1 & 6.1 \\
\hline Outer diameter (tip, mm) & 6.5 & 6.5 & 6.5 & 6.5 & 6.5 & 6.5 \\
\hline Inner diameter (tip, mm) & 4.2 & 4.2 & 4.2 & 4.2 & 4.2 & 4.2 \\
\hline Pitch (mm) & 2.8 & 2.8 & 2.8 & 2.8 & 2.8 & 2.8 \\
\hline Canulla width (mm) & - & 2 & 2 & 2 & 2 & 2 \\
\hline No. of fin & - & 2 & 2 & 4 & 4 & - \\
\hline Fin length (mm) & - & 20 & 40 & 20 & 40 & - \\
\hline Distal hole length (mm) & - & - & - & - & - & 10 \\
\hline
\end{tabular}

STD, standard pedicle screw; CAN, cannulated screw. 


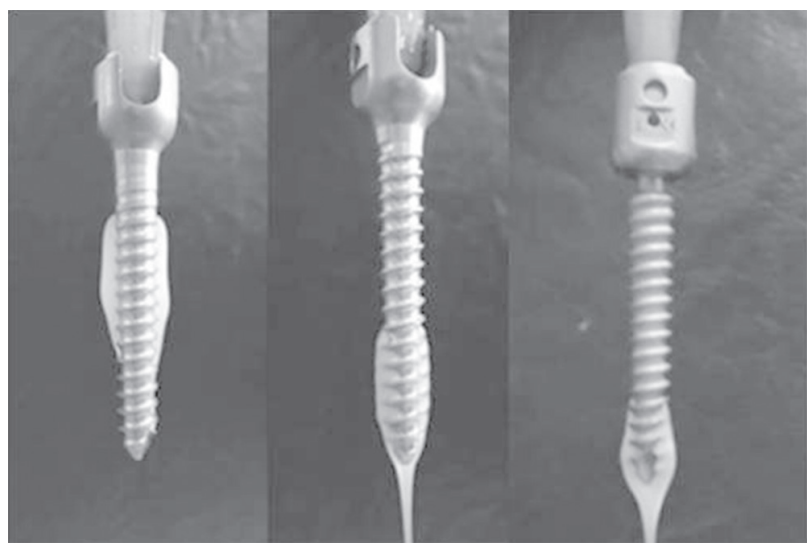

Fig. 3. Injection of cement through the cannula of an expandable screw.

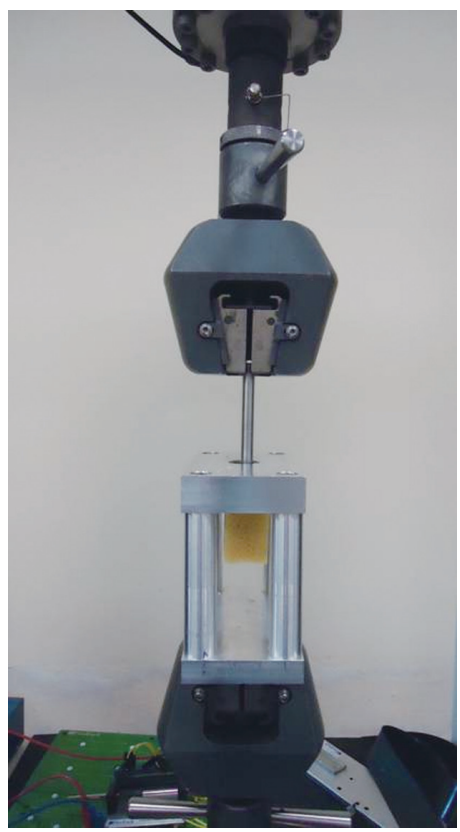

Fig. 4. Fixture frame with a test block held in the INSTRON device.

to judge when the cement has reached a viscosity appropriate for extrusion. This does not occur until after the cement has begun to thicken. A small amount of cement should be extruded from the syringe and visually assessed to ensure that the surface appears dull and excessive flow under gravity has ceased [12]. After injection of the cement, an expansion pin was inserted into the expandable screws for fin expansion. The foam block was held in a fixture frame prior to the application of a longitudinal extraction load to the screw head at a loading rate of $5 \mathrm{~mm} /$ min, conforming to ASTM F1691-96 [13]. An INSTRON Model 3382 device was used, and the peak pullout force was recorded (Fig. 4). As the screws were extracted, the

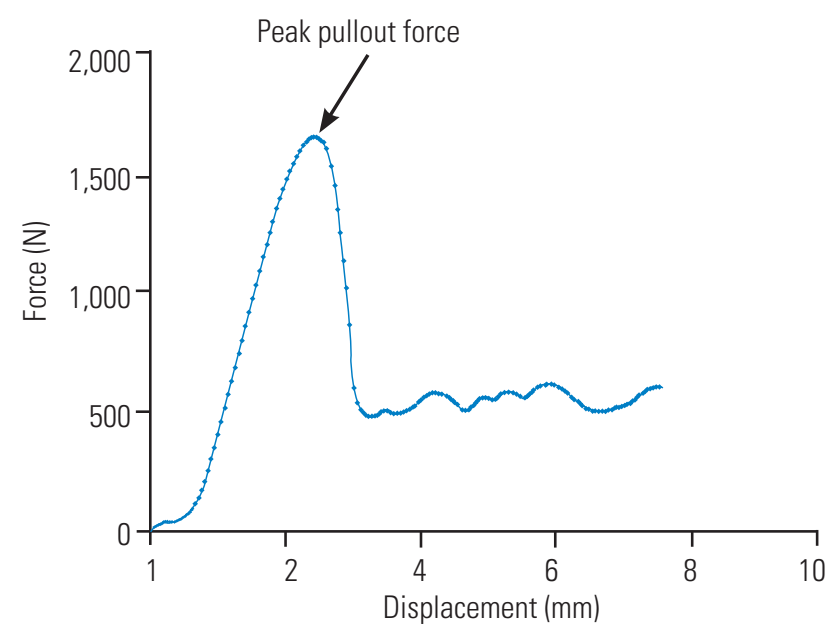

Fig. 5. Load displacement curve of a polymethylmethacrylate-augmented expandable pedicle screw.

load increased sharply at first and then rapidly dropped. When the screw stripped the polyurethane foam, the peak load recorded just before the rapid drop in the load deformation curve was defined as the peak pullout force (Fig. 5).

\section{Statistical analysis}

Analysis of variance was used to compare the differences of bending strength and pullout strength among the study groups and was conducted using SPSS software ver. 13.0 (SPSS Inc., Chicago, IL, USA). The level of significance was defined as $p<0.05$.

\section{Results}

\section{Nonaugmented expandable screws}

An increase from two to four fins, with the same fin length, significantly affected the peak pullout force. An increase in fin length, with the same fin number, also increased the peak pullout force, but the increase was not statistically significant. The $4 \mathrm{~F} 40-\mathrm{mm}$ screws had the greatest peak pullout force, and it was significantly greater than that of the $2 \mathrm{~F} 20-\mathrm{mm}$ and $2 \mathrm{~F} 40-\mathrm{mm}$ screws. The number of fins was thus the design variable most strongly associated with an increase in the pullout force (Table 3).

\section{Cannulated versus nonaugmented expandable screws}

No significant difference was found in the performance of PMMA-augmented cannulated screws and the (best per- 
forming) $4 \mathrm{~F}$ 40-mm nonaugmented expandable screws. Calcium phosphate-augmented cannulated screws had

Table 3. Comparison of peak pullout forces of nonaugmented expandable screws

\begin{tabular}{|c|c|}
\hline Screws & Comparison \\
\hline $2 \mathrm{~F} 20 \mathrm{~mm}$ vs. $2 \mathrm{~F} 40 \mathrm{~mm}$ & Not significant \\
\hline $2 \mathrm{~F} 20 \mathrm{~mm}$ vs. $4 \mathrm{~F} 20 \mathrm{~mm}$ & $p<0.01$ \\
\hline 2F 20 mm vs. $4 \mathrm{~F} 40 \mathrm{~mm}$ & $p<0.001$ \\
\hline $2 F 40 \mathrm{~mm}$ vs. 4F $20 \mathrm{~mm}$ & Not significant \\
\hline 2F $40 \mathrm{~mm}$ vs. $4 \mathrm{~F} 40 \mathrm{~mm}$ & $p<0.01$ \\
\hline 4F $20 \mathrm{~mm}$ vs. $4 \mathrm{~F} 40 \mathrm{~mm}$ & Not significant \\
\hline
\end{tabular}

The comparison shows that the increase in fin number is more effective than the increase in fin length. significantly lower peak pullout forces than nonaugmented 4F 40-mm screws $(p<0.001)$.

\section{Augmented expandable screws}

Both calcium phosphate and PMMA-augmented 4F 40$\mathrm{mm}$ pedicle screws had significantly greater peak pullout forces than the other expandable screws $(p<0.001)$.

\section{All groups}

PMMA-augmented 4F 40-mm screws had significantly greater peak pullout forces than the other screws $(p<0.001)$. All other test screws had significantly greater

Table 4. Test results showing the pedicle screw pullout force in Newtons

\begin{tabular}{lrrr} 
Group & Mean \pm standard deviation & Maximum & Minimum \\
\hline 1 & $839.5 \pm 29.217$ & 883 & 796 \\
\hline 2 & $1,041.1 \pm 53.236$ & 1,114 & 952 \\
\hline 3 & $1,073.6 \pm 53.475$ & 1,150 & 1,041 \\
\hline 4 & $1,125.6 \pm 38.053$ & 1,174 & 1,072 \\
\hline 5 & $1,154.1 \pm 46.867$ & 1,211 & 1,243 \\
\hline 6 & $1,309.7 \pm 41.838$ & 1,380 & 1,465 \\
\hline 7 & $1,512.5 \pm 33.577$ & 1,580 & 1,270 \\
\hline 8 & $1,326.2 \pm 34.695$ & 1,392 & 1,597 \\
\hline 9 & $1,629.7 \pm 24.954$ & 1,676 & 1,100 \\
\hline 10 & $1,178.6 \pm 42.301$ & 1,242 & 1,242 \\
\hline 11 & $1,285.6 \pm 23.129$ & 1,312 & 1,188 \\
\hline 12 & $1,211 \pm 17.901$ & 1,246 & 1,280 \\
\hline 13 & $1,330.8 \pm 33.773$ & 1,380 & 1,096 \\
\hline 14 & $1,167.1 \pm 52.583$ & 1,241 & 964 \\
\hline 15 & $1,015.1 \pm 34.220$ & 1,079 & \\
\hline
\end{tabular}
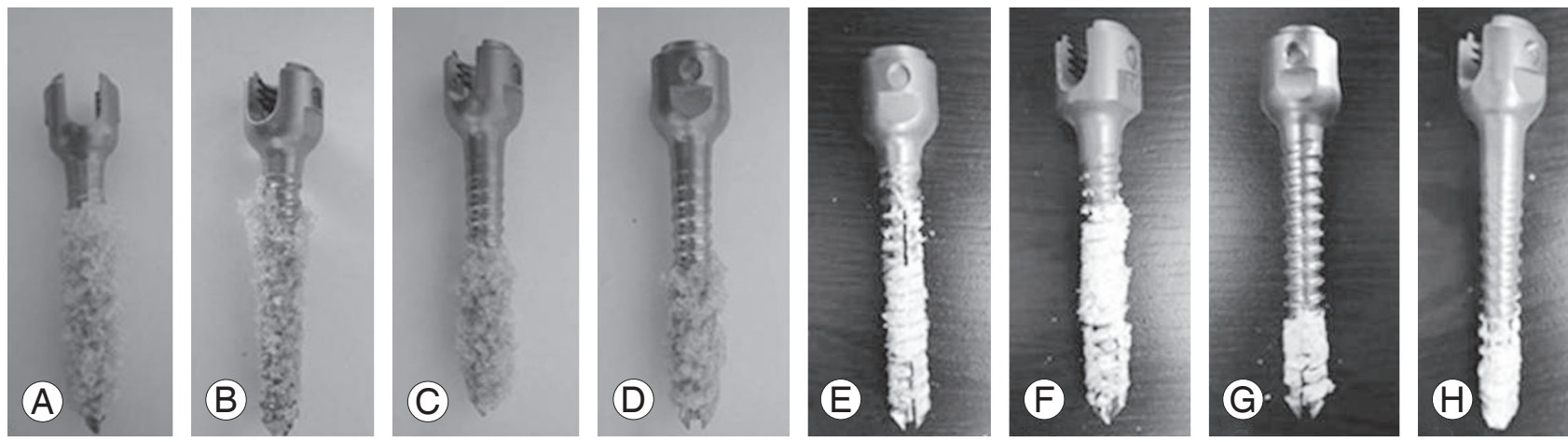

Fig. 6. (A-D) Polymethylmethacrylate-augmented expandable screws after extraction. (A, B) 40-mm finned screws. (C, D) 20-mm finned screws. (EH) Calcium phosphate-augmented expandable screws after extraction. (E, F) 40-mm finned screws. (G, H) 20-mm finned screws. 


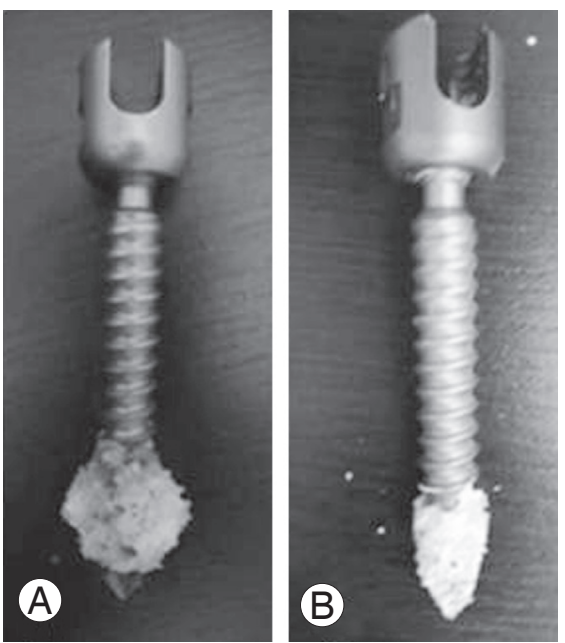

Fig. 7. (A) Polymethylmethacrylate-augmented cannulated screw after extraction. (B) Calcium phosphate-augmented cannulated screw after extraction.

peak pullout forces than the standard pedicle screw (Table 4). Examination of the extracted augmented screws revealed that increases in fin length and fin number allowed the augmentation material to spread more widely within the polyurethane foam (Fig. 6), and minimum spread was seen with the cannulated screws (Fig. 7).

Finite element analysis of the pedicle screw results with a commercially available software (Algor Simulation Software ver. 23.1; Algor Inc., Pittsburgh, PA, USA) generated three-dimensional surface models of the screws by a helical sweep of a predetermined thread. The surface models were transformed to solid models by a Boolean operation. The screws were inserted into the center of polyethylene cylinders to simulate a bending test condition. The screw and cylinder materials were assumed to be linearly isotropic and were map-meshed with 8-node hexahedral elements, except for irregular contact surfaces, which were free-meshed with high-order 20-node hexahedral elements. The overall element size was $0.4 \mathrm{~mm}$. Surfaceto-surface contact elements with a frictional coefficient of zero were used to represent the interface between the pedicle screw and polyethylene, and axial rotation of the screws was not allowed. A simulated vertical force applied to the heads of the fully inserted screws heads showed that 40-mm long fins created a weak point on the screw neck (Fig. 8).

\section{Discussion}

Although PMMA cement augmentation is widely used

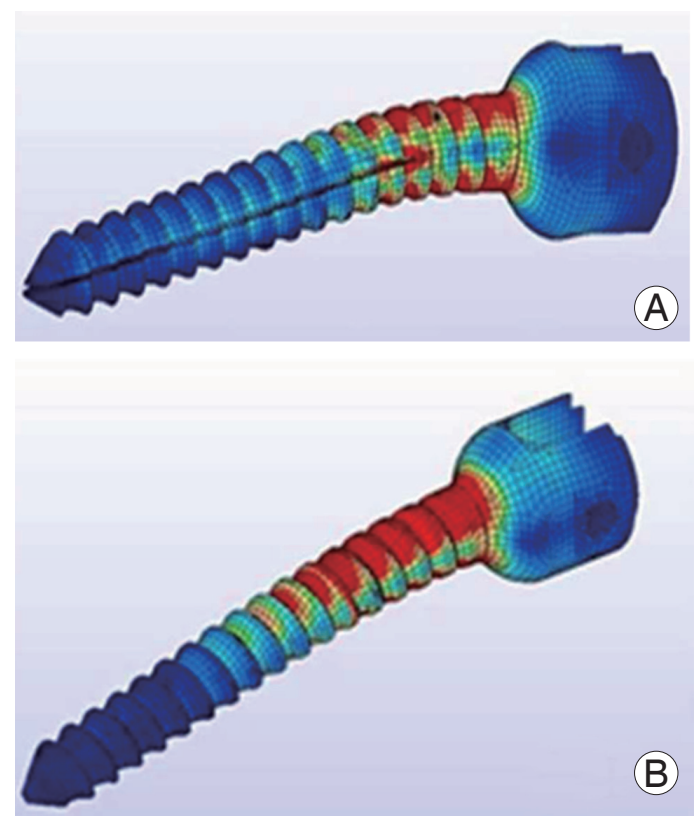

Fig. 8. Maximal vertical bending force on a fully inserted screw (in red). (A) Expandable pedicle screw with 40-mm long fins. Screw bending and breakage close to the fins. (B) Standard pedicle screw under the same amount of vertical bending force with no breakage and minimal bending.

in orthopedic surgery to strengthen the bone-screw interface $[7,14,15]$, its use in spinal surgery is recent. One reason for the delayed adoption of PMMA in spinal surgery is the risk of thermal necrosis caused by the exothermic polymerization reaction of PMMA. The leakage of liquid PMMA into the spinal canal during surgery can lead to permanent thermal damage to the spinal cord [16]. Polymerized PMMA is not biodegradable, and any remaining in the spinal canal would become a permanent stenosing mass [17-19]. Toxic damage associated with PMMA has been reported [20]; however, not much concern has been generated because of its established use in orthopedic surgery.

Synthetic bone substitutes are nontoxic, do not generate exothermic reactions, are biodegradable, and have osteoconductive effects. They have been used to augment pedicle screws $[5,6]$, but have the disadvantage of needing 3-24 hours to achieve maximum compressive strength. They are very resistant to direct compressive force but are brittle and have low shear and bending strength. Unlike calcium-based cement, PMMA achieves maximal compressive strength in minutes, thereby allowing surgeons to perform corrective compression, distraction, and rotation maneuvers with confidence [14]. PMMA augmentation 
is assumed to provide a better peak pullout strength than calcium-based cement. Although Rohmiller et al. [21] found calcium sulfate cement to be as effective as PMMA for augmenting pedicle screws, their test method did not conform to the ASTM. Our results are in line with previous results showing that PMMA augmentation provided the greatest peak pullout force.

Cannulated pedicle screws were originally designed to allow PMMA augmentation by pressurized injection through the central cannula and dispersion from the distal opening of the screw $[7,8]$. No data are available on the augmentation of cannulated pedicle screws with calcium-based cement. In the present study, both PMMAand calcium phosphate-augmented cannulated screws had greater peak pullout strength than standard pedicle screws. PMMA augmentation was superior to calcium phosphate augmentation, but no significance difference in pullout strength was found between nonaugmented expandable screws and PMMA-augmented cannulated screws. Cannulated screws used in spinal surgery are designed to allow PMMA passage from the distal end of the screws [22-24]. In a biomechanical study, Chen et al. [25] found that as the number of holes in proximal positions was increased, PMMA spread over a larger area and the peak pullout force significantly increased. This suggests that changes in the design of the cannulated screws used in the present study might increase its pullout force.

Expandable screws do not take longer to apply than standard pedicle screws and do not extend the surgical procedure in elderly patients, but their effectiveness in severely osteoporotic bone has not been established. Cook et al. [2] suggested augmenting expandable screws in severely osteoporotic bone to achieve adequate fixation. The effect of fin number on the performance of expandable screws is unknown. Cook et al. [2,3] evaluated four-finned screws; Lei and $\mathrm{Wu}$ [4] and Liu et al. [26] evaluated twofinned screws and standard pedicle screws. The screws used in those studies were cylindrical, and pretapping was required before insertion. As pretapping adversely affects the bone-screw interface in osteoporotic patients [27-29], conical screws, which do not require pretapping, were used in the present study.

The 4F 40-mm expandable pedicle screws showed the best results, but fatigue tests must be performed before in vivo use. Finite element analysis showed that the point of maximal stress was located close to fins and a failure site when vertical force was applied to fully inserted screws in simulations. The 40-mm fins might thus reduce the durability of screws.

The augmentation of expandable or cannulated screws prolongs the surgical procedure. The preparation and application of the augmentation material takes time and can adversely affect the surgical outcomes of patients with comorbidities. Because of the small time window for the application of the augmentation material, an additional preparation time may be required as the number of augmented screws increases. PMMA augmentation may also complicate the removal of screws in revision surgeries.

The study limitations include the use of test blocks to simulate human osteoporotic cancellous bone. The blocks provide a uniform and stable test ground but do not fully represent the properties of human vertebrae. Spinal vertebrae have cortical bone that may affect the pullout measurements differently as under physiological situations, loads are cyclic and multidirectional. Therefore, failure patterns associated with loading in cadaveric bone or animal models should be the investigated in future studies. Nevertheless, the test design used in the present study provided valuable data on the pullout strength of screws immediately after insertion.

An increase in both fin number and length had a positive effect on the peak pullout strength of expandable screws. An increase in the fin number as the only design change in the expandable screws significantly increased the peak pullout force. Fin length had a minor effect on the peak pullout force as an increased fin length resulted in a nonsignificant improvement in the peak pullout force.

\section{Conclusions}

Expandable pedicle screws had greater peak pullout forces than standard pellicle screws and had the advantage of augmentation with either PMMA or calcium-based cement.

\section{Conflict of Interest}

No potential conflict of interest relevant to this article was reported.

\section{References}

1. Babat LB, McLain RF, Bingaman W, Kalfas I, Young P, Rufo-Smith C. Spinal surgery in patients with Par- 
kinson's disease: construct failure and progressive deformity. Spine (Phila Pa 1976) 2004;29:2006-12.

2. Cook SD, Salkeld SL, Stanley T, Faciane A, Miller SD. Biomechanical study of pedicle screw fixation in severely osteoporotic bone. Spine J 2004;4:402-8.

3. Cook SD, Barbera J, Rubi M, Salkeld SL, Whitecloud TS 3rd. Lumbosacral fixation using expandable pedicle screws. an alternative in reoperation and osteoporosis. Spine J 2001;1:109-14.

4. Lei W, Wu Z. Biomechanical evaluation of an expansive pedicle screw in calf vertebrae. Eur Spine J 2006;15:321-6.

5. Derincek A, Wu C, Mehbod A, Transfeldt EE. Biomechanical comparison of anatomic trajectory pedicle screw versus injectable calcium sulfate graftaugmented pedicle screw for salvage in cadaveric thoracic bone. J Spinal Disord Tech 2006;19:286-91.

6. Evans SL, Hunt CM, Ahuja S. Bone cement or bone substitute augmentation of pedicle screws improves pullout strength in posterior spinal fixation. J Mater Sci Mater Med 2002;13:1143-5.

7. Frankel BM, Jones T, Wang C. Segmental polymethylmethacrylate-augmented pedicle screw fixation in patients with bone softening caused by osteoporosis and metastatic tumor involvement: a clinical evaluation. Neurosurgery 2007;61:531-7.

8. Moon BJ, Cho BY, Choi EY, Zhang HY. Polymethylmethacrylate-augmented screw fixation for stabilization of the osteoporotic spine: a three-year follow-up of 37 patients. J Korean Neurosurg Soc 2009;46:30511.

9. Allen RF, Baldini NC, Donofrio PE, et al. Standard specification for rigid polyurethane foam for use as a standard material for testing orthopedic devices and instruments (F1839-97). West Conshohocken (PA): The American Society for Testing and Materials; 1998.

10. Li B, Aspden RM. Composition and mechanical properties of cancellous bone from the femoral head of patients with osteoporosis or osteoarthritis. J Bone Miner Res 1997;12:641-51.

11. Patel PS, Shepherd DE, Hukins DW. Compressive properties of commercially available polyurethane foams as mechanical models for osteoporotic human cancellous bone. BMC Musculoskelet Disord 2008;9:137.

12. Vaishya R, Chauhan M, Vaish A. Bone cement. J Clin
Orthop Trauma 2013;4:157-63.

13. Allen RF, Baldini NC, Donofrio PE, et al. Standard test method for determining axial pull-out strength of medical bone screws (F1691-96). In: American Society for Testing and Materials, editor. Annual book of ASTM standards: medical devices and services. West Conshohocken (PA): American Society for Testing and Materials; 1998.

14. Chang MC, Liu CL, Chen TH. Polymethylmethacrylate augmentation of pedicle screw for osteoporotic spinal surgery: a novel technique. Spine (Phila Pa 1976) 2008;33:E317-24.

15. Burval DJ, McLain RF, Milks R, Inceoglu S. Primary pedicle screw augmentation in osteoporotic lumbar vertebrae: biomechanical analysis of pedicle fixation strength. Spine (Phila Pa 1976) 2007;32:1077-83.

16. Fan HT, Zhang RJ, Shen CL, et al. The biomechanical properties of pedicle screw fixation combined with trajectory bone cement augmentation in osteoporotic vertebrae. Clin Spine Surg 2016;29:78-85.

17. Amendola L, Gasbarrini A, Fosco M, et al. Fenestrated pedicle screws for cement-augmented purchase in patients with bone softening: a review of 21 cases. J Orthop Traumatol 2011;12:193-9.

18. Wilkes RA, Mackinnon JG, Thomas WG. Neurological deterioration after cement injection into a vertebral body. J Bone Joint Surg Br 1994;76:155.

19. Yeom JS, Kim WJ, Choy WS, Lee CK, Chang BS, Kang JW. Leakage of cement in percutaneous transpedicular vertebroplasty for painful osteoporotic compression fractures. J Bone Joint Surg Br 2003;85:83-9.

20. Sturup J, Nimb L, Kramhoft M, Jensen JS. Effects of polymerization heat and monomers from acrylic cement on canine bone. Acta Orthop Scand 1994;65:20-3.

21. Rohmiller MT, Schwalm D, Glattes RC, Elalayli TG, Spengler DM. Evaluation of calcium sulfate paste for augmentation of lumbar pedicle screw pullout strength. Spine J 2002;2:255-60.

22. Chang MC, Kao HC, Ying SH, Liu CL. Polymethylmethacrylate augmentation of cannulated pedicle screws for fixation in osteoporotic spines and comparison of its clinical results and biomechanical characteristics with the needle injection method. J Spinal Disord Tech 2013;26:305-15.

23. Colman M, Pond J, Bachus K, Lawrence BD, Spiker 
WR, Brodke DS. Fenestrated screws augmented with PMMA increase the pullout strength of sacral pedicle screws. Clin Spine Surg 2017;30:E252-6.

24. Chen LH, Tai CL, Lee DM, et al. Pullout strength of pedicle screws with cement augmentation in severe osteoporosis: a comparative study between cannulated screws with cement injection and solid screws with cement pre-filling. BMC Musculoskelet Disord 2011;12:33.

25. Chen LH, Tai CL, Lai PL, et al. Pullout strength for cannulated pedicle screws with bone cement augmentation in severely osteoporotic bone: influences of radial hole and pilot hole tapping. Clin Biomech (Bristol, Avon) 2009;24:613-8.

26. Liu D, Wu ZX, Pan XM, et al. Biomechanical comparison of different techniques in primary spinal surgery in osteoporotic cadaveric lumbar vertebrae: expansive pedicle screw versus polymethylmethacrylate-augmented pedicle screw. Arch Orthop Trauma Surg 2011;131:1227-32.

27. Abshire BB, McLain RF, Valdevit A, Kambic HE. Characteristics of pullout failure in conical and cylindrical pedicle screws after full insertion and backout. Spine J 2001;1:408-14.

28. Pfeiffer FM, Abernathie DL, Smith DE. A comparison of pullout strength for pedicle screws of different designs: a study using tapped and untapped pilot holes. Spine (Phila Pa 1976) 2006;31:E867-70.

29. Ono A, Brown MD, Latta LL, Milne EL, Holmes DC. Triangulated pedicle screw construct technique and pull-out strength of conical and cylindrical screws. J Spinal Disord 2001;14:323-9. 